\title{
Blockade of fructose transporter protein GLUT5 inhibits proliferation of colon cancer cells: proof of concept for a new class of anti-tumor therapeutics
}

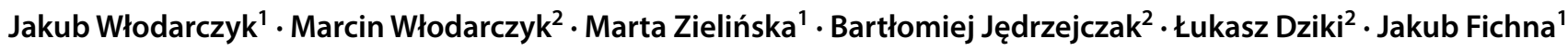

Received: 6 January 2021 / Revised: 30 April 2021 / Accepted: 18 May 2021 / Published online: 29 May 2021

(c) The Author(s) 2021

\begin{abstract}
Background Despite the fact that colorectal cancer (CRC) is one of the most commonly diagnosed cancers in men and women, its current treatment remains unsatisfactory and therefore novel studies proposing new approaches are necessary. A high sugar diet is believed to promote carcinogenesis. Fructose is absorbed from the gastrointestinal tract by members of the glucose transporter family-GLUT. The aim of the study was to characterize the expression of GLUT5 at mRNA level in CRC patients. Moreover, our goal was to elucidate the molecular role of GLUT5 in CRC and assess whether GLUT5 inhibitor may affect the viability of colon cancer cells.

Methods The expression of GLUT5 at mRNA level was characterized based on 30 samples from resected colorectal cancers and 30 healthy colonic mucosa specimens from surgical margins. The inhibitory effect of $\mathrm{N}$-[4-(methylsulfonyl)2-nitrophenyl]-1,3-benzodioxol-5-amine (MSBNA) was assessed on a colon cancer cell line, HT-29, and normal colon epithelium cells-CCD $841 \mathrm{CoN}$ Cells.

Results GLUT5 expression was found in $96.7 \%$ of cancer specimens and only in $53.3 \%$ of healthy mucosa fragments. In cancer tissue, real-time PCR analysis showed almost 2, fivefold $(p<0.001)$ increase of GLUT5 mRNA expression level compared with the healthy intestinal mucosa. GLUT5 inhibitor, MSNBA $(10 \mu \mathrm{M})$ significantly decreased the viability of colon cancer cells, while barely affected the viability of normal colon epithelium cells.

Conclusions Our study suggests that a strong focus should be put on GLUT5 and its inhibitors for both diagnostic and therapeutic purposes in CRC.
\end{abstract}

Keywords Colorectal cancer · Fructose $\cdot$ GLUT5 $\cdot N$-[4-(methylsulfonyl)-2-nitrophenyl]-1,3-benzodioxol-5-amine

\section{Introduction}

Colorectal cancer (CRC) is the third most commonly diagnosed cancer in men (746,000 new cases per year) and the second in women $(614,000$ new cases per year). It is also the second leading cause of cancer-related deaths in Western countries [1]. Many people with CRC do not experience

Jakub Włodarczyk and Marcin Włodarczyk contributed equally to this work.

Jakub Włodarczyk

jakub.wlodarczyk@umed.lodz.pl

1 Department of Biochemistry, Medical University of Lodz, Mazowiecka 6/8, 92-215 Lodz, Poland

2 Department of General and Colorectal Surgery, Medical University of Lodz, Żeromskiego 113, 90-549 Lodz, Poland any symptoms in the early disease stages or these symptoms are nonspecific (weakness, fatigue, diarrhea/constipation), therefore it is diagnosed mainly in the advanced stage [2]. Late diagnosis in CRC leads to an increase in mortality and morbidity rates and although new detection and treatment strategies are regularly proposed, CRC still poses a great threat to human health [3].

Although currently, the most effective strategies in CRC treatment are surgery, radiotherapy, and chemotherapy, their outcomes still remain unsatisfactory [4]. Moreover, despite recent advances in the management of $\mathrm{CRC}$, metastatic disease remains challenging and patients are rarely cured. The 5-year survival rate for patients with CRC is $64 \%$, whereas in metastatic CRC it is only $14 \%$ [5]. Recently, the role of targeted therapy in the management of patients with CRC has gained more attention. Multiple studies proposed new treatment approaches such as inhibitors of angiogenesis, 
EGFR- or BRAF mutation-targeted therapies, and other strategies, including immunotherapy [6].

Apart from age, male sex, and hereditary factors, diet is the most important risk factor which is responsible for $35 \%$ of CRC incidence [7]. Consumption of sugars is increasing worldwide [8] and its association with cancer is still unknown, yet possible. It has been suggested that a high sugar diet may promote carcinogenesis by stimulation of insulin and insulin-like growth factor-I synthesis [9], induction of oxidative stress [10] or promotion of weight gain [11].

About $10 \%$ of calories contained in the Western diet are supplied by fructose (approximately $55 \mathrm{~g} /$ day) [12] which is absorbed from the gastrointestinal tract through passive transport across cell membranes by members of the glucose transporter family-GLUT. The GLUT family consists of 14 members divided into three major classes based on sequence homology and substrate selectivity [13]. GLUT5 (class II) and GLUT2 (class I) are the major fructose transporters in the body. The former is the sole transporter specific for fructose with no ability to transport glucose or galactose.

Recently, new design options for novel therapeutics against obesity, diabetes, and cancer have been opened due to the synthesis of a specific inhibitor of human GLUT5 [14]. For example, in a human breast cancer cell line MCF7, MSNBA decreased competitively inhibited GLUT5 fructose uptake and, in consequence, cell viability.

The aim of the study was to determine the expression of GLUT5 at mRNA level in CRC patients in different stages of cancer. Moreover, our goal was to elucidate the molecular role of GLUT5 in CRC and assess whether GLUT5 inhibitor may affect the viability of colon cancer cells.

\section{Materials and methods}

\section{Patients}

This prospective clinical study was performed in adult CRC patients, hospitalized at the Department of General and Colorectal Surgery at the Medical University of Lodz, Poland. We enrolled 30 patients in different stages of CRC. All approvals required to perform this study were obtained from the Committee of Bioethics of Medical University of Lodz (RNN/831/14/KB). The study enrolled only the patients hospitalized with the diagnosis of CRC who gave their written and informed consent to participate. The case report form for each patient qualified for the study including demographic data, progression, and stage of CRC (Table 1).
Table 1 Patients' demography and cancer characteristics

\begin{tabular}{ll}
\hline Age & 60.9 years \\
Sex & \\
Male & $N=15$ \\
Female & $N=15$ \\
Localization & \\
Sigmoid & $N=12$ \\
Descending colon & $N=6$ \\
Transverse colon & $N=6$ \\
Ascending colon & $N=6$ \\
Grade & \\
G1 & $N=7$ \\
$\quad$ G2 & $N=16$ \\
G3 & $N=7$ \\
Stage & \\
II & $N=10$ \\
III & $N=10$ \\
IV & $N=10$ \\
\hline
\end{tabular}

\section{Collection of colonic biopsies and quantification of GLUT5 expression}

To quantify GLUT5 expression, forceps tissue samples from resected colorectal cancers and healthy colonic mucosa from surgical margins were collected immediately after surgical operation. After isolation of tissue, the biopsy specimens were immediately frozen and kept at $-80{ }^{\circ} \mathrm{C}$ until processing.

\section{RNA isolation}

Total RNA isolation was performed using commercially available TRIsureTM (Bioline, Australia). Colon samples were minced and homogenized in TRIsureTM. After centrifugation and phases separation, the aqueous phase was mixed 3:1 (v/v) with isopropanol and loaded on the column. The subsequent steps were conducted according to the manufacturer's protocol. The quality and quantity of RNA were estimated spectrophotometrically with BioPhotometer Plus (Eppendorf, Germany). The RNA was characterized with A260/A280 ratio, which was in the range of 1.70-2.00.

\section{Reverse transcription and quantitative real-time PCR}

cDNA synthesis was performed with a High-Capacity cDNA Reverse Transcription Kit (Applied Biosystems, USA) in accordance with the manufacturer's protocol. Total RNA 
$(1 \mu \mathrm{g})$ was used in reverse transcription reaction with the following incubation steps: $25^{\circ} \mathrm{C}$ for $10 \mathrm{~min}, 37^{\circ} \mathrm{C}$ for $120 \mathrm{~min}$ and $85^{\circ} \mathrm{C}$ for $5 \mathrm{~min}$ for RNA. The quantification of mRNA was performed using the real-time PCR method with FAM dye-labeled TaqMan ${ }^{\circledR}$ probes (Applied Biosystems, USA). The reaction mixture consisted of cDNA, TaqMan ${ }^{\circledR}$ Master Mix II, no UNG, TaqMan ${ }^{\circledR}$ Assays and RNase-free water in a total volume of $10 \mu \mathrm{l}$. The cycle parameters for TaqMan® Assays were as follows: initial denaturation at $95{ }^{\circ} \mathrm{C}$ for $10 \mathrm{~min}$, followed by 40 cycles of sequential incubations at $95{ }^{\circ} \mathrm{C}$ for $15 \mathrm{~s}$ and at $60{ }^{\circ} \mathrm{C}$ for $1 \mathrm{~min}$. The obtained results were normalized to the expression of GAPDH (glyceraldehyde 3-phosphate dehydrogenase) for the studied genes. All experiments were performed as triplicates. The real-time PCR was performed using Master Realplex4s (Eppendorf, Germany). The fluorescent dye emission was a function of the cycle number. The initial amount of the temple was evaluated as a $\mathrm{Ct}$ parameter. The $\mathrm{Ct}$ value corresponded to the threshold cycle number at which PCR amplification reached a significant threshold. The relative expression level was calculated as $2^{-\Delta \mathrm{Ct}} \times 1000$. The results are expressed as the number of examined mRNA copies per 1000 copies of mRNA for GAPDH.

\section{Cell culture}

The colon cancer cell line HT-29 and normal colon epithelium CCD $841 \mathrm{CoN}$ cells were obtained from the American Type Culture Collection (ATCC HTB-38 and CRL-1790). The cells were cultured in Dulbecco's modified Eagle's medium supplemented with 10\% FBS 1\% L-glutamine and $1 \%$ Penicillium, Neomycin, and Streptomycin (Gibco, Life Technologies). The cells grew at $37{ }^{\circ} \mathrm{C}$ in a humidified atmosphere and $5 \% \mathrm{CO}_{2}$, according to the standards procedures. For all experiments, colon cell lines were seeded onto 96-well plates and cultured for 2 or 3 days. Prior to the following analysis, the expression of GLUT5 receptor on both HT-29 and CoN cells on a transcript level was confirmed.

\section{Cell viability}

The cell viability was analyzed using cell MTT Cell Viability Assay Kit. The test was performed according to the manufacturer's protocol. The cells were seeded in 96-well tissue culture plates to reach optimal density (48-72 h). Then the cells were incubated with $(5 \mathrm{mM}$ fructose; $10 \mathrm{mM}$ fructoseconsidering the maximum possible plasma concentration at postprandial condition; $2 \mathrm{mM}$ MSNBA-GLUT5 inhibitor; control group) and $10 \mu \mathrm{l}$ of MTT for $4 \mathrm{~h}$ at $37^{\circ} \mathrm{C}$. Next, 200 $\mu \mathrm{L}$ of DMSO was added directly into the medium in each well and pipetted up and down several times to dissolve the formazan salt. The final volume in the well was $300 \mu \mathrm{l}$. The absorbance signal was measured on a spectrophotometer at $570 \mathrm{~nm}$, while background absorbance was measured at $630 \mathrm{~nm}$. The whole assay was performed in six technical replicates and in three biological replicates.

\section{Statistical analysis}

The statistical analysis was performed in Prism 8.0 (GraphPad Software Inc). $p$ values $<0.05$ were considered statistically significant. A Shapiro-Wilk test was used to test the determined normality of the distribution of variables; continuous variables were expressed as mean \pm SD (standard deviation). The statistical significance between the groups was determined using unpaired $t$ test or two-way ANOVA followed by Tukey's post hoc test. The Spearman's rho correlation coefficient was used to determine the correlation between the GLU5 mRNA expression level and the cancer grade and stage, which was determined according to the American Joint Committee on Cancer (AJCC) criteria.

\section{Results}

\section{mRNA levels}

We analyzed the expression of GLUT5 at the mRNA level in $30 \mathrm{CRC}$ samples and 30 healthy intestinal mucosa biopsy specimens from surgical margins. Reference GAPDH gene expression was detectable in all 60 analyzed samples. Noteworthy, GLUT5 expression was found in $96.7 \%$ of cancer specimens and only in $53.3 \%$ of healthy mucosa fragments. In the cancer tissue, the real-time PCR analysis showed almost a 2.5-fold increase of GLUT5 mRNA expression level compared with healthy intestinal mucosa

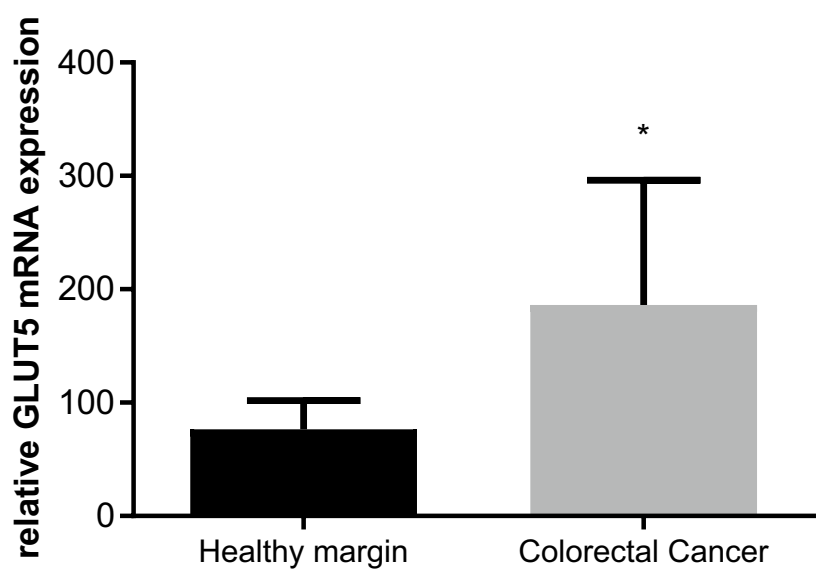

Fig. 1 GLUT5 expression at the mRNA level in samples from CRC tissue and from healthy margin colon mucosa. Data are expressed as mean \pm SD. *Significant difference at $p<0.001$ relative to the healthy margin. Statistical significance was determined using unpaired $t$ test 
Table 2 Correlation between GLUT5 relative expression in cancer tissue and tumor grade and stage assessed by Spearman's rho correlation

\begin{tabular}{|c|c|c|c|c|c|c|}
\hline \multirow{2}{*}{$\begin{array}{l}\text { GLUT5 relative } \\
\text { gene expression }\end{array}$} & \multicolumn{3}{|l|}{ Grade } & \multicolumn{3}{|l|}{ Stage } \\
\hline & $\mathrm{G} 1(n=7)$ & $\mathrm{G} 2(n=16)$ & $\mathrm{G} 3(n=7)$ & II $(n=10)$ & III $(n=10)$ & IV $(n=10)$ \\
\hline Mean \pm SD & $130.84 \pm 65.05$ & $168.25 \pm 103.19$ & $277.59 \pm 128.86$ & $133.16 \pm 62.05$ & $189.89 \pm 132.67$ & $232.06 \pm 119.00$ \\
\hline$p$ & 0.0309 & & & 0.0663 & & \\
\hline Correlation rho & 0.3946 & & & 0.3396 & & \\
\hline
\end{tabular}

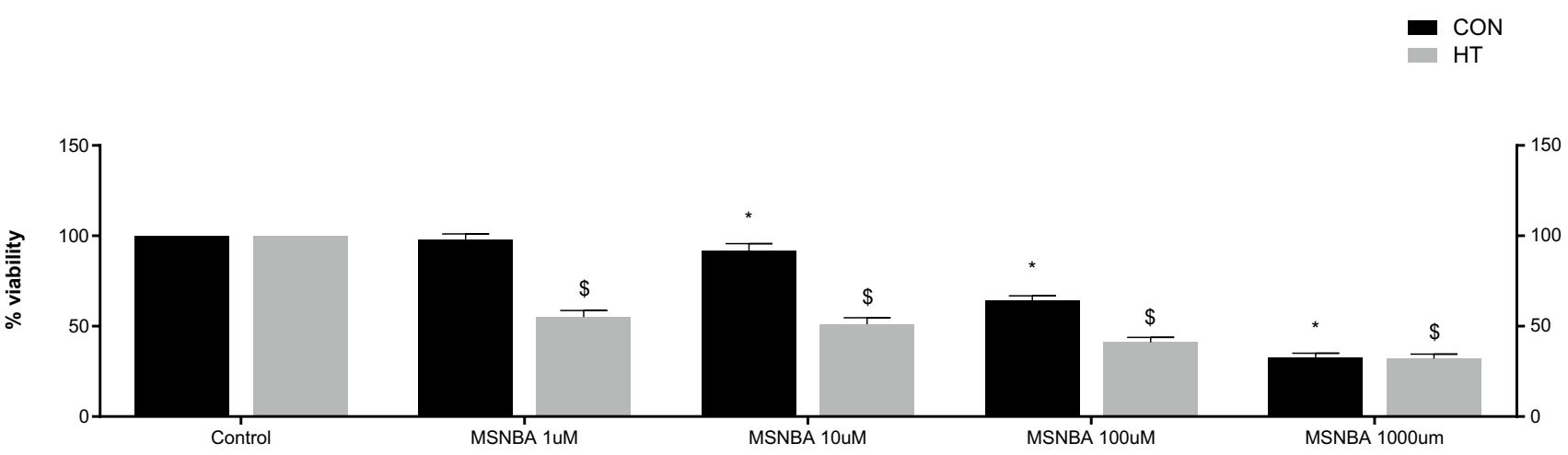

Fig. 2 Cytotoxicity evaluation of MSNBA in HT-29 and CoN cells. Cells were exposed to MSNBA at various concentrations for $24 \mathrm{~h}$, and then cell viability was detected by MTT assay. Data are expressed

(Fig. 1). The mean relative expression of GLUT5 in CRC was significantly higher $(186.1 \pm 110.1)$, whereas its expression in healthy margins was lower $(76.38 \pm 25.5 ; P<0.001$; $t=3.911$ ).

Thirty cases of colorectal cancer were analyzed using Spearman's correlation analysis to determine the relationship between GLUT5 mRNA expression level and cancer grade and stage. As shown in Table 2, GLUT5 expression level showed a significant positive correlation with cancer grade.

\section{Cell viability}

A preliminary study confirmed the expression of the GLUT5 receptor on both HT-29 and CoN cells on a transcript level. The relative expression of GLUT5 on HT-29 and CoN cells was, respectively, 0.31 and 0.23 .

A $24 \mathrm{~h}$ incubation of HT-29 cells with GLUT5 inhibitor, MSNBA, significantly decreased their viability (51\% decrease with $10 \mu \mathrm{M}$ and $55 \%$ with $1 \mu \mathrm{M}$ MSNBA), while CoN cells were only slightly affected by these concentrations of MSNBA (respectively 92 and $98 \%$ ), as assessed by twoway ANOVA (effect of MSNBA: $F_{4,50}=1278.8, p<0.001$; effect of HT-29 cells: $F_{1,50}=1125.94, p<0.001$; interaction between MSNBA and HT-29: $F_{4,50}=206.09, p<0.001$ ), followed by Tukey's post hoc test (Fig. 2). IC50 value for HT-29 cells was significantly lower than for CoN cells $(0.25 \mu \mathrm{M} \pm 0.08$ vs. $12.51 \mu \mathrm{M} \pm 1.41 ; p<0.001 ; t=-15.08)$. as mean $\pm \mathrm{SD}(n=6)$. Statistical significance from the two-way ANOVA, Tukey's post hoc test: ${ }^{*} p<0.001$ versus CoN control group; ${ }_{p} p<0.001$ versus HT-29 control group

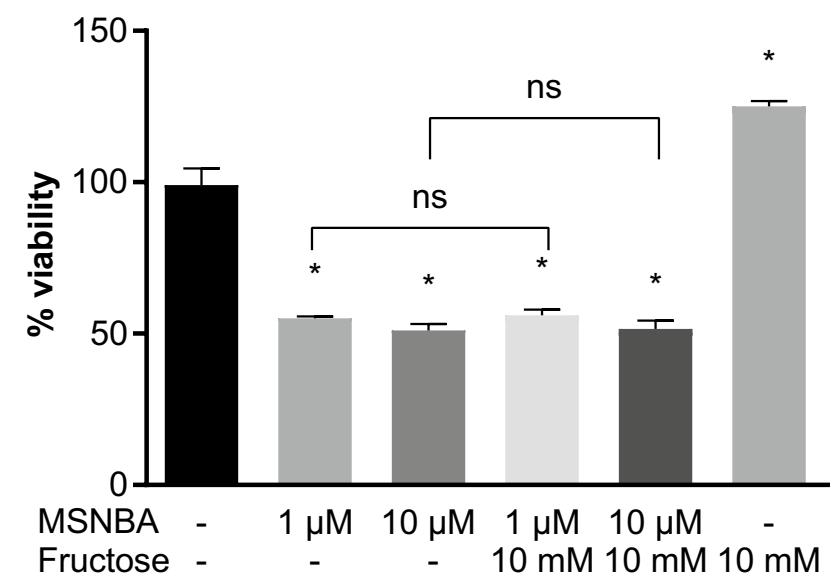

Fig. 3 Cytotoxicity evaluation of MSNBA and fructose in HT-29. Cells were exposed to MSNBA and fructose at various concentrations for $24 \mathrm{~h}$, and then cell viability was detected by MTT assay. Data are expressed as mean $\pm S D(n=4)$. Statistical significance from the twoway ANOVA, Tukey's post hoc test: $* p<0.001$ versus control group

The addition of $10 \mathrm{mM}$ fructose with MSNBA in the same concentrations did not affect HT-29 cell viability (respectively, 52 and 54\%), as assessed by two-way ANOVA (effect of MSNBA: $F_{2,18}=254.164, p<0.001$; effect of fructose: $F_{1,18}=7.403, p=0.014$; interaction between MSNBA and fructose: $F_{2,18}=10.519, p<0.001$ ), followed by Tukey's post hoc test. However, when the cells 
were incubated with $10 \mathrm{mM}$ fructose alone, their viability increased to $125 \%$ (Fig. 3).

The incubation for $48 \mathrm{~h}$ with MSNBA did not change the viability of HT-29 cells (50\% viability-10 $\mu$ M MSNBA; $53 \%$ viability-1 $\mu \mathrm{M}$ MSNBA, compared with $24 \mathrm{~h}$ incubation) (Fig. 4). CoN cells displayed similar viability to $24 \mathrm{~h}$ incubation-91\% after $10 \mu \mathrm{M}$ MSNBA and $96 \%$ viability after $1 \mu \mathrm{M}$ MSNBA exposure for $48 \mathrm{~h}$. As assessed by twoway ANOVA (effect of time: $F_{1,60}=2.5, p=0.1187$; interaction between time and HT-29: $F_{1,60}=0.043, p=0.8358$; interaction between time and MSNBA: $F_{2,60}=0.9$, $p=0.3972$; interaction between time, HT-29 and MSNBA: $F_{2,60}=0.7, p=0.4825$ ), followed by Tukey's post hoc test.

\section{Discussion}

The aim of the study was to characterize the expression of GLUT5 in healthy colon mucosa and colon cancer tissue, as well as to assess whether GLUT5 inhibitor, $\mathrm{N}$-[4(methylsulfonyl)-2-nitrophenyl]-1,3-benzodioxol-5-amine (MSNBA), might decrease the viability of colon cancer cells in vitro. We found that the GLUT5 expression was higher in carcinomatous colon tissues than in the healthy resected margins. Our study also showed that MSNBA has a significant effect on reducing colon cancer cell viability while barely affecting healthy intestinal epithelial cells.

The GLUT family consists of 14 members, which are extensively described in the literature. Many of them play a significant physiological role in the gastrointestinal tract $[15,16]$, being responsible for absorption of monosaccharides in the intestine, which is crucial for caloric intake. The activity of the GLUT family is adjusted in accordance with food supply, food composition, and energy demand in diverse physiological and pathophysiological situations. In addition, GLUT5 was proved to be present in a normal colon epithelium [17].

The literature confirms that GLUT5 overexpression may be linked to pathologies, such as hypertension, renal diseases, and hepatic dysregulations [18]. It was also found that GLUT5 is expressed in numerous cancerous tissues, particularly breast, renal, liver, and testicular cancer [17]. Breast cancer cells have been shown to express GLUT5 at higher mRNA and protein levels than healthy breast tissue. A similar pattern of GLUT5 expression was observed in renal cell carcinoma compared to healthy cells [19]. Moreover, in in vitro studies Caco2 cells and highly proliferative cancer cells were characterized by GLUT5 expression, which may be seen as as a potential marker of malignancy or high proliferation rate [20]. Our study indicated that GLUT5 is expressed in colon carcinoma and its expression is significantly increased in comparison to healthy colonic tissue. Moreover, the GLUT5 expression is positively correlated with cancer grade. This is the first study to evidence the possible role of GLUT5 in colon carcinogenesis and indicates the transporter's diagnostic and therapeutic potential.

It needs to be noted that the role of fructose in cancer cell biology and the importance of GLUT5 in fructose-related cellular processes have been already indicated [21, 22]. For example, studies showed that, due to increased metabolism, cancer cells increased calories/energy demand and the usage of fructose and other monosaccharides escalated in these cells [23]. Moreover, recent reports have suggested that overexpression of GLUT5 in cancer tissues is positively correlated with fructose uptake [24]. This may be related either to the presence of GLUT5 or to an increased usage of fructose: the former leads to greater use of fructose by neoplastic cells, while the latter results in a higher abundance of GLUT5. In most of the tumor cells overexpressing GLUT5, the rate of fructose uptake is exacerbated, indicating that fructose may be the preferred substrate providing the energy required for growth and proliferation. More
Fig. 4 Cytotoxicity evaluation of MSNBA and time of incubation in HT-29. Cells were exposed to MSNBA at various concentrations for 24 or $48 \mathrm{~h}$, and then cell viability was detected by MTT assay. Data are expressed as mean $\pm \mathrm{SD}$ $(n=6)$. Statistical significance from the two-way ANOVA followed by Tukey's post hoc test

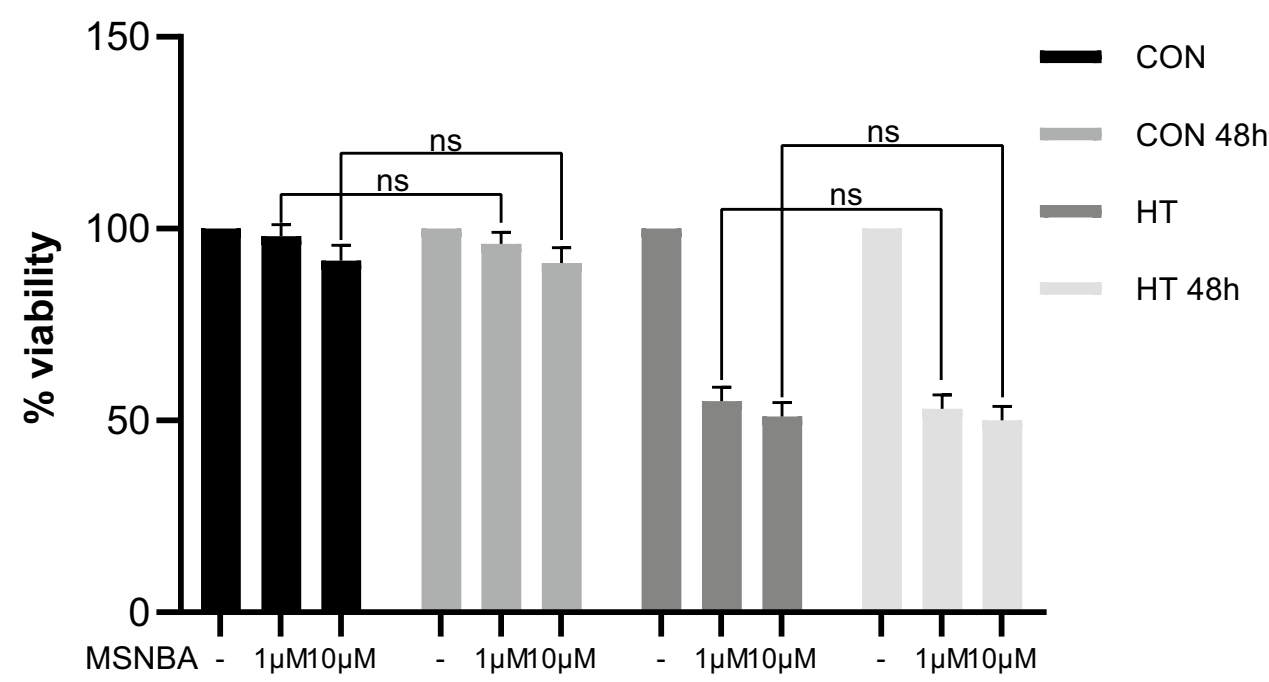


recently, GLUT5 has been linked not only to cancer growth and energy expenditure but also to cancer cell migration induced by metabolic changes and the development of drug resistance [25]. This effect is mediated by AKT1 and AKT3 activation and miR-125b-5p downregulation. What is more, GLUT5 silencing with small interfering RNA attenuated mesenchymal marker expression and migratory activity in drug-resistant colon cancer cells. Additionally, the treatment with 2,5-anhydro-D-mannitol, a competitive inhibitor of fructose uptake, resensitized chemoresistant cancer cells to oxaliplatin and 5-fluorouracil. It was thus proposed that GLUT5 expression after chemotherapy can serve as a new marker to indicate metabolic change-induced migration and drug resistance development. This also strongly suggests that the inhibitors of GLUT5 may constitute a future therapeutic approach in colorectal or other cancers.

Excessive consumption of fructose, for which GLUT5 is the sole transporter, is associated with an increased risk of CRC [26]. A recent study was focused on the effects of daily oral administration of high-fructose corn syrup (HFCS) in adenomatous polyposis coli (APC) mutant mice, which are predisposed to develop intestinal tumors [27]. According to Goncalves et al., the HFCS-treated mice showed a substantial increase in tumor size and tumor grade. Within the tumors, fructose was converted to fructose-1-phosphate, leading to activation of glycolysis and increased synthesis of fatty acids that support tumor growth. Blocking the fructose transporter (GLUT5) may inhibit this process and therefore stop colon cancer growth. In the second part of our study, we evidenced that inhibition of GLUT5 by MSNBA efficiently decreased the viability of colon cancer cells, which may be used to design an experimental treatment of CRC as well as to prevent CRC growth. However, the future investigation of MSNBA and its impact on CRC is still necessary.

Lately, a novel modulator of GLUT5 has been proposed. As a ligand-activated transcription factor, liver $\mathrm{X}$ receptor $\alpha(\operatorname{LXR} \alpha)$ might provide novel pharmacologic strategies for the selective modulation of GLUT5 activity in the treatment of both metabolic disease and cancer [28]. It was proved to have a strong impact on the expression of GLUT5 in the intestine. Additionally, a whole-cell-based GLUT5 assay system amenable to high-throughput ligand screening has recently become available, enabling an accelerated discovery of future GLUT5 inhibitors [29]. While we have proved that GLUT5 inhibitor, MSNBA, decreases colon cancer cells viability, novel GLUT5 modulators may have a stronger impact on carcinogenesis in the intestines.

\section{Conclusions}

Fructose, accounting for $\sim 5-15 \%$ of daily calorie intake, is linked with various morbidities, including tumorigenesis, obesity, diabetes, as well as heart and kidney diseases [30].
Studies revealed a fructose correlation with increased risk of breast cancer progression and metastasis [31]. In pancreatic tissue, it has been confirmed that fructose can be utilized for the synthesis of nucleic acid and to promote cell proliferation by cancer cells [32]. In the future, the mentioned morbidities may constitute a global health problem, as they are correlated with the increasing worldwide fructose intake. Therefore, novel therapeutics are required. Our study suggests that a strong focus could be put on GLUT5 and its inhibitors for both, diagnostic and therapeutic purposes in CRC. What follows, this subject matter warrants further investigations.

Acknowledgements GLUT5 inhibitor (MSNBA)-N[4-(methylsulfonyl)-2-nitrophenyl]-1,3-benzodioxol-5- amine was synthesized by TriMen Chemicals S.A.

Author contributions Project administration: JW and JF. Participated in research design: JW, MW, MZ, JF. Conducted experiment: JW, MZ, BJ, ŁD. Wrote an original draft preparation: JW, MW. Performed data analysis: JW, MW. Edited and reviewed: MW, MZ, ŁD, JF.

Funding This research was funded by the Medical University of Lodz, Granty UMEDu (564/1-000-00/564-20-022, to JW) and Medical University of Lodz (503/1-156-04/503-11-001-19-00, to JF).

\section{Declaration}

Conflict of interest The authors declared that they have no conflict of interest.

Open Access This article is licensed under a Creative Commons Attribution 4.0 International License, which permits use, sharing, adaptation, distribution and reproduction in any medium or format, as long as you give appropriate credit to the original author(s) and the source, provide a link to the Creative Commons licence, and indicate if changes were made. The images or other third party material in this article are included in the article's Creative Commons licence, unless indicated otherwise in a credit line to the material. If material is not included in the article's Creative Commons licence and your intended use is not permitted by statutory regulation or exceeds the permitted use, you will need to obtain permission directly from the copyright holder. To view a copy of this licence, visit http://creativecommons.org/licenses/by/4.0/.

\section{References}

1. Ferlay J, Soerjomataram I, Dikshit R, Eser S, Mathers C, Rebelo $\mathrm{M}$, et al. Cancer incidence and mortality worldwide: sources, methods and major patterns in GLOBOCAN 2012. Int J Cancer. 2015;136:E359-86. https://doi.org/10.1002/ijc.29210.

2. Stintzing S. Management of colorectal cancer. F1000Prime Rep. 2014;6:108. https://doi.org/10.12703/P6-108.

3. Siegel R, Ward E, Brawley O, Jemal A. Cancer statistics, 2011. CA Cancer J Clin. 2011;61:212-36. https://doi.org/10.3322/caac. 20121.

4. Kuipers EJ, Grady WM, Lieberman D, Seufferlein T, Sung JJ, Boelens PG, et al. Colorectal cancer. Nat Rev Dis Prim. 2015. https://doi.org/10.1038/nrdp.2015.65. 
5. Colorectal Cancer: StatisticsICancer. Net https://www.cancer.net/ cancer-types/colorectal-cancer/statistics. Accessed 23 Oct 2020

6. Xie YH, Chen YX, Fang JY. Comprehensive review of targeted therapy for colorectal cancer. Signal Transduct Target Ther. 2020;5:1-30. https://doi.org/10.1038/s41392-020-0116-z.

7. Brenner H, Kloor M, Pox CP. Colorectal cancer. Lancet. 2014;383:1490-502. https://doi.org/10.1016/S0140-6736(13) 61649-9.

8. Stewart B, Wild CP. World Cancer Report 2014. Lyon: International Agency for Research on Cancer; 2014.

9. Tasevska N, Jiao L, Cross AJ, Kipnis V, Subar AF, Hollenbeck A, et al. Sugars in diet and risk of cancer in the NIH-AARP Diet and Health Study. Int J Cancer. 2012;130:159-69. https://doi.org/10. 1002/ijc. 25990.

10. Van Cutsem E, Nordlinger B, Cervantes A. ESMO Guidelines Working Group. Advanced colorectal cancer: ESMO Clinical Practice Guidelines for treatment. Ann Oncol. 2010;21:v93-7. https://doi.org/10.1093/annonc/mdq222.

11. Ristvedt SL, Pruitt SL, Trinkaus KM. Appraisal of emerging symptoms of colorectal cancer: associations with dispositional, demographic, and tumor characteristics. J Behav Med. 2014;37:698-708. https://doi.org/10.1007/s10865-013-9519-4.

12. Ferrier DR. Lippincott illustrated reviews: Biochemistry. 7 th ed. Walters Kluwer: Lippincott; 2020.

13. Manolescu AR, Witkowska K, Kinnaird A, Cessford T, Cheeseman C. Facilitated hexose transporters: new perspectives on form and function. Physiology (Bethesda). 2007;22:234-40. https://doi. org/10.1152/physiol.00011.2007.

14. George Thompson AM, Ursu O, Babkin P, Iancu CV, Whang A, Oprea TI, et al. Discovery of a specific inhibitor of human GLUT5 by virtual screening and in vitro transport evaluation. Sci Rep. 2016;6:1-9. https://doi.org/10.1038/srep24240.

15. Koepsell H. Glucose transporters in the small intestine in health and disease. Pflugers Arch Eur J Physiol. 2020;472:1207-48. https://doi.org/10.1007/s00424-020-02439-5.

16. Merigo F, Brandolese A, Facchin S, Missaggia S, Bernardi P, Boschi F, et al. Glucose transporter expression in the human colon. World J Gastroenterol. 2018;24:775-93. https://doi.org/ 10.3748/wjg.v24.i7.775.

17. Godoy A, Ulloa V, Rodríguez F, Reinicke K, Yañez AJ, de los García MA, et al. Differential subcellular distribution of glucose transporters GLUT1-6 and GLUT9 in human cancer: ultrastructural localization of GLUT1 and GLUT5 in breast tumor tissues. J Cell Physiol. 2006;207:614-27. https://doi.org/10.1002/jcp. 20606.

18. Douard V, Ferraris RP. The role of fructose transporters in diseases linked to excessive fructose intake. J Physiol. 2013;591:401-14. https://doi.org/10.1113/jphysiol.2011.215731.

19. Medina Villaamil V, Aparicio Gallego G, Valbuena Rubira L, García Campelo R, Valladares-Ayerbes M, Grande Pulido E, et al.
Fructose transporter Glut5 expression in clear renal cell carcinoma. Oncol Rep. 2011;25:315-23. https://doi.org/10.3892/or. 2010.1096.

20. Douard V, Ferraris RP. Regulation of the fructose transporter GLUT5 in health and disease. Am J Physiol Endocrinol Metab. 2008;295:227-37. https://doi.org/10.1152/ajpendo.90245.2008.

21. Nakagawa T, Lanaspa M, Millan IS, Fini M, Rivard C, SanchezLozada L, et al. Fructose contributes to the Warburg effect for cancer growth. Cancer Metab. 2020;8:16. https://doi.org/10.1186/ s40170-020-00222-9.

22. Weng Y, Zhu J, Chen Z, Fu J, Zhang F. Fructose fuels lung adenocarcinoma through GLUT5 comment. Cell Death Dis. 2018. https://doi.org/10.1038/s41419-018-0630-x.

23. Santhekadur PK. The dark face of fructose as a tumor promoter. Genes Dis. 2020;7:163-5. https://doi.org/10.1016/j.gendis.2019. 10.001 .

24. Weng Y, Fan X, Bai Y, Wang S, Huang H, Yang H, et al. SLC2A5 promotes lung adenocarcinoma cell growth and metastasis by enhancing fructose utilization. Cell Death Discov. 2018;4:38. https://doi.org/10.1038/s41420-018-0038-5.

25. Park G-B, Jeong J-Y, Kim D. GLUT5 regulation by AKT1/3-miR$125 \mathrm{~b}-5 \mathrm{p}$ downregulation induces migratory activity and drug resistance in TLR-modified colorectal cancer cells. Carcinogenesis. 2020;41:1329-40. https://doi.org/10.1093/carcin/bgaa074.

26. Charrez B, Qiao L, Hebbard L. The role of fructose in metabolism and cancer. Horm Mol Biol Clin Investig. 2015;22:79-89. https:// doi.org/10.1515/hmbci-2015-0009.

27. Goncalves MD, Lu C, Tutnauer J, Hartman TE, Hwang SK, Murphy CJ, et al. High-fructose corn syrup enhances intestinal tumor growth in mice. Science. 2019;363:1345-9. https://doi.org/10. 1126/science.aat8515.

28. Zwarts I, van Zutphen T, Kruit JK, Liu W, Oosterveer MH, Verkade HJ, et al. Identification of the fructose transporter GLUT5 (SLC2A5) as a novel target of nuclear receptor LXR. Sci Rep. 2019;9:1-10. https://doi.org/10.1038/s41598-019-45803-X.

29. Thomik T, Wittig I, Choe JY, Boles E, Oreb M. An artificial transport metabolon facilitates improved substrate utilization in yeast. Nat Chem Biol. 2017;13:1158-63. https://doi.org/10.1038/nchem bio. 2457.

30. Port AM, Ruth MR, Istfan NW. Fructose consumption and cancer. Curr Opin Endocrinol Diabetes Obes. 2012;19:367-74. https:// doi.org/10.1097/MED.0b013e328357f0cb.

31. Fan X, Liu H, Liu M, Wang Y, Qiu L, Cui Y. Increased utilization of fructose has a positive effect on the development of breast cancer. PeerJ. 2017. https://doi.org/10.7717/peerj.3804.

32. Liu H, Huang D, McArthur DL, Boros LG, Nissen N, Heaney AP. Fructose induces transketolase flux to promote pancreatic cancer growth. Cancer Res. 2010;70:6368-76. https://doi.org/10.1158/ 0008-5472.CAN-09-4615. 